\title{
HUBUNGAN SELF-REGULATED LEARNING, KEMAMPUAN KOMUNIKASI, DAN VOCATIONAL SKILLS DENGAN KEMAMPUAN ADAPTASI TERHADAP DUNIA KERJA PADA SISWA SEKOLAH MENENGAH KEJURUAN
}

\author{
Sisco Agustian, Setiadi Cahyono Putro, Hari Putranto \\ Universitas Negeri Malang, Jalan Semarang 5 Malang 65145 \\ Email: nocsis30@gmail.com
}

\begin{abstract}
The purpose of this research is to determine the relationship between self-regulated learning (X1), communication ability (X2) and vocational skills (X3) with adaptation ability into the professional world $(\mathrm{Y})$. This research uses descriptive correlational research design. The sample of this research is student of Department of Electrical Power Instalation Engineering at vocational high school regional malang which has done industry practices a number of 96 respondents. In conducting this research, the writer collects the data by using the questionnaires. The Results of the data that have tested the validity and reliability which is obtained from the questionnaire scores filled by the respondents. Data analysis technique uses partial correlation analysis and linear regression. From the research results are obtained the regression equation $\mathrm{Y}=17.818+0.448 \mathrm{X} 1+0.351 \mathrm{X} 2-0,1 \mathrm{X} 3$ with a significance of 0.000 which means there is a positive and significant relationship between $\mathrm{X} 1, \mathrm{X} 2$, and $\mathrm{X} 3$ with $\mathrm{Y}$ simultaneously.
\end{abstract}

Keywords: self regulated learning, communication ability, vocational skills, adaptation ability, working

\begin{abstract}
Abstrak: Tujuan dari penelitian ini yaitu untuk mengetahui hubungan antara self regulated learning (X1), kemampuan komunikasi (X2), dan vocational skills (X2) dengan kemampuan adaptasi terhadap dunia kerja (Y). Penelitian ini menggunakan rancangan penelitian deskriptif korelasional. Sampel penelitian ini adalah siswa Jurusan Teknik Instalasi Tenaga Listrik di Sekolah Menengah Kejuruan (SMK) Kota Malang yang telah melakukan prakerin sejumlah 96 responden. Teknik pengumpulan data pada penelitian mengunakan angket. Hasil data angket yang telah memenuhi uji validitas dan reliabilitas yang didapatkan dari skor nilai angket yang diisi oleh responden. Teknik analisis data menggunakan analisis korelasi parsial dan regresi linier. Dari hasil penelitian didapat persamaan regresi $Y=17,818+0,448 \mathrm{X} 1+0,351 \mathrm{X} 2-0,1 \mathrm{X} 3$ dengan signifikansi sebesar 0,000 yang artinya ada hubungan positif dan signifikan antara $\mathrm{X} 1$, $\mathrm{X} 2$, dan X3 dengan Y secara simultan.
\end{abstract}

Kata kunci: self regulated learning, kemampuan komunikasi, vocational skills, kemampuan adaptasi, bekerja

Lingkungan yang terus berubah secara dinamis akan membuat manusia berusaha mempertahankan kehidupannya dengan melakukan adaptasi (Putro, 2017). Schneiders mengungkapkan adaptasi meliputi beberapa aspek, yaitu: mekanisme pertahanan diri yang minimal berarti bersedia mengakui kegagalan yang dialami dan berusaha kembali untuk mencapai target dalam bekerja, kemampuan untuk belajar dan memanfaatkan masa lalu berarti pengalaman pada masa lalu sebagai pembelajaran agar siswa dapat menganalisis faktorfaktor yang dapat membantu ataupun mengganggu strategi untuk dapat menyelesaikan pekerjaan secara efektif dan efisien (Puspitasari, 2015).

Runyon dan Haber menegaskan bahwa adaptasi memiliki beberapa aspek, yaitu: gambaran diri yang positif diartikan sebagai persepsi yang diberikan oleh orang lain dan siswa terhadap dirinya sendiri agar memiliki persepsi diri yang baik sehingga siswa mampu merasakan kenyamanan 
psikologis dan lebih percaya diri dalam bekerja; dan kemampuan mengekspresikan emosi dengan baik berarti kemampuan untuk memilih emosi dalam memberikan respons terhadap masalah yang dihadapi siswa (Marganingtias, 2009). Dengan kontrol emosi yang baik, maka siswa dapat memecahkan masalah yang muncul secara intelegen, dan hubungan interpersonal yang baik berarti siswa memiliki kemampuan berkomunikasi yang baik terhadap lingkungan sosial sehingga bisa mengatasi masalah yang muncul di tempat kerja.

Blanchard dan Herseymemaparkan diperlukan kemampuan konseptual, kemampuan sosial, dan kemampuan teknis untuk memiliki kemampuan adaptasi yang baik (Kristiani, dkk., 2013; Gunawan, 2017). Zimmerman dalam penelitian yang telah dilakukannya, mengemukakan bahwa kemampuan konseptual merupakan kemampuan untuk mengatur, merencanakan, menginstruksikan diri, memonitor dan melakukan evaluasi terhadap aktivitas belajar untuk mencapai tujuan atau disebut self-regulated learning (SRL) (Probowati, 2015; Gunawan dan Palupi, 2012).

Mengadaptasi dari model Zimmerman disimpulkan bahwa SRL terdiri dari tiga fase, yaitu: forethought phase, performance phase, dan self relfection phase. Forethought phase adalah kegiatan untuk menganalisa tugas yang diberikan, menetapkan strategi serta memunculkan dan menguatkan motivasi individu. Performance phase untuk memantau kesesuaian strategi belajar yang direncanakan melalui pemantauan diri dan kontrol pikiran dengan keterlakasanaannya dalam mencapai tujuan belajar serta kamampuan untuk bersikap fleksibel ketika menghadapi suatu masalah. Self-reflection phase untuk melakukan refleksi serta evaluasi atas ketercapaian strategi belajar yang telah dilaksanakan. Sehingga pengalaman belajar serta kemampuan siswa dalam mengelola respon emosional dalam menerima kegagalan atau kesuksesan dapat diperoleh.

Siswa dengan miliki SRL yang tinggi, diharapkan dapat memanfaatkan pengalaman untuk mencapai tingkatan yang lebih tinggi dalam mengatur diri dilingkungan kerja serta dengan pengetahuan yang baik tentang dirinya menunjang adaptasinya terhadap dunia kerja. Jhonson menjelaskan kemampuan komunikasi terdiri dari keterampilan dasar yang perlu dimiliki agar mampu memulai, mengembangkan, dan memelihara hubungan yang akrab dengan orang lain sehingga tercipta lingkungan sosial yang baik, hal ini dianggap meningkatkan kemampuan adaptasi terhadap dunia kerja (Sanjaya, 2010). Sementara itu Rogers dan Kincaid menyatakan pertukaran informasi antara komunikator dan komunikan sebagai partisipan sama-sama aktif dalam merumuskan isi pesan dan dapat dimengerti serta disetujui oleh kedua pihak (Kartiwa, 2012).

Keterampilan berkomunikasi antara lain kemampuan untuk memahami merupakan kemauan untuk saling percaya, mempunyai keberanian untuk membagikan perasaan, mempunyai kesadaran diri untuk mengubah perilaku yang salah serta adanya penerimaan terhadap kegagalan maupun kesuksesan yang terjadi adalah akibat dari dirinya (Permatasari dan Gamayanti 2016). Wolpe menegaskan kemampuan mengomunikasikan pikiran dan perasaan secara tepat dan jelas untuk menyampaikan pendapat kepada lingkungannya (Purita, 2015; Gunawan dan Benty, 2017). Sementara itu Jhonson menegaskan kemampuan memberi dukungan merupakan kemampuan merespons yang bersifat mendukung pesan komunikator, seperti memberikan saran, simpati, pendapat atau support (Sanjaya, 2010). Kemampuan dalam menyelesaikan konflik untuk memberikan solusi terhadap sebuah masalah yang terjadi secara konstruktif.

Siswa dengan adanya kemampuan komunikasi, diharapkan dapat mempunyai hubungan interpersonal yang baik dengan orang lain ditempat kerja, dapat bekerja sama dengan baik, mampu memahami orang lain dengan baik, dan mampu menyampaikan perasaan sehingga tercipta kenyamanan dalam bekerja yang akan menunjang efisiensi kerja. Dengan diperolehnya hal tersebut, berarti siswa dapat beradaptasi dengan baik. Kemampuan teknis dalam dunia SMK disebut vocational skills. Moedzakir mendefinisikan vocational skills sebagai keterampilan yang terkait dengan pekerjaan atau profesi (Haludhi, 2016).

Kemendikbud (2017) dalam keputusan struktur kurikulum yang digunakan di SMK terdapat beberapa kompetensi keahlian yang harus dimiliki oleh siswa SMK sebelum melakukan prakerin adalah Teknik instalasi motor listrik, teknik instalasi penerangan listrik, dan teknik 
instalasi tenaga listrik. Keterampilan yang dimiliki diharapkan dapat berperan dalam menyelesaikan pekerjaan secara efektif dan efisien. Sehingga tugastugas yang diberikan dapat diselesaikan dengan baik sesuai dengan target yang telah ditentukan. Hal tersebut berarti siswa dapat melakukan adaptasi dengan baik terhadap lingkungan kerjanya.

Oleh karena itu, kemungkinan self-regulated learning, kemampuan komunukasi, dan vocational skills mempunyai pengaruh dengan kemampuan adaptasi terhadap dunia kerja. Jika siswa mempunyai self-regulated learning yang baik, ditunjang kemampuan komunikasi yang baik serta vocational skills yang tinggi, maka diharapkan dapat meningkatkan kemampuan adaptasi terhadap dunia kerja siswa. Tujuan dari penelitian ini adalah: (1) mengungkap hubungan antara self-regulated learning; kemampuan komunikasi; vocational skills secara parsial dengan kemampuan adaptasi terhadap dunia kerja; (2) mengungkap hubungan antara self-regulated learning dan kemampuan komunikasi; self-regulated learning dan vocational skills; kemampuan komunikasi dan vocational skills; self-regulated learning, kemampuan komunikasi, dan vocational skills secara simultan dengan kemampuan adaptasi terhadap dunia kerja.

\section{METODE}

Berdasarkan tujuan penelitian, penelitian ini menggunakan pendekatan kuantitatif korelasional. Sampel dalam penelitian ini sejumlah 96 responden. Teknik penentuan sampel menggunakan simple random sampling. Teknik pengumpulan data penelitian menggunakan angket tertutup. Analisis data menggunakan analisis regresi ganda. Uji prasyarat analisis dilakukan dengan menguji normalitas, linearitas, multikolinearitas, autokorelasi, dan heterokedastisitas (Gunawan, 2016; Gunawan, 2013). Setelah data dinyatakan memenuhi uji prasyarat analisis, selanjutnya dilakukan uji hipotesis dengan regresi linier ganda. Pengambilan keputusan dilakukan dengan taraf signifikansi 0,05 . Analisis data dilakukan dengan bantuan program IBM SPSS Statistics 23 .

\section{HASIL}

Data hasil penelitian untuk variabel kemampuan adaptasi terhadap dunia kerja diperoleh: rata-rata 59,30; standar deviasi 6,603; skor terendah 44; dan skor tertinggi 73. Sebaran data variabel kemampuan adaptasi terhadap dunia kerja ditunjukkan pada Tabel 1.

Data hasil penelitian variabel self-regulated learning diperoleh: rata-rata 63,69; standar deviasi 6,584; skor terendah 49; dan skor tertinggi 78 . Sebaran data variabel self-regulated learning ditunjukkan pada Tabel 2.

Data hasil penelitian variabel kemampuan komunikasi diperoleh: rata-rata 42,39; standar deviasi 5,147; skor terendah 31; dan skor tertinggi 53. Sebaran data variabel kemampuan komuniasi ditunjukkan pada Tabel 3.

Data hasil penelitian variabel vocational skills diperoleh: rata-rata 105,40; standar deviasi 12,930; skor terendah 75; dan skor tertinggi 132. Sebaran data variabel vocational skills ditunjukkan pada Tabel 4.

Data sebelum diuji dengan analisis regresi ganda, terlebih dahulu diuji asumsi data yakni dengan uji normalitas, linearitas, multikolinearitas, autokorelasi, dan heterokedastisitas. Hasil uji normalitas dengan kolmogorov-smirnov masingmasing variabel $\mathrm{Y}, \mathrm{X}_{1}, \mathrm{X}_{2}$ dan $\mathrm{X}_{3}$ berturut-turut diperoleh nilai $(p)$ yaitu: 0,$200 ; 0,200 ; 0,200 ; 0,192$. Dimana setiap variabel memiliki nilai $(p)$ tersebut $>0,05$ yang artinya data terdistribusi normal. Hasil uji linearitas diperoleh bahwa $\mathrm{X}_{1}$ dengan $\mathrm{Y}$ terjadi hubungan linear dengan nilai $p$ sebesar 0,000 . Untuk $\mathrm{X}_{2}$ dengan $\mathrm{Y}$ terjadi hubungan yang linear dengan nilai $\mathrm{p}$ sebesar 0,005 . Sedangkan untuk $\mathrm{X}_{3}$ dengan $\mathrm{Y}$ terjadi hubungan yang linear dengan nilai p sebesar 0,017 .

Hasil uji multikolinearitas diperoleh nilai tolerance $\mathrm{X}_{1} \mathrm{X}_{2}$, dan $\mathrm{X}_{3}$ secara berturut-turut yaitu 0,$313 ; 0,583$; dan 0,451 yang nilainya masingmasing $>0,10$ dan nilai VIF $\mathrm{X}_{1} \mathrm{X}_{2}$, dan $\mathrm{X}_{3}$ secara berturut-turut yaitu 3,$19 ; 1,71 ; 2,22$ yang masingmasing nilainya $<10$. Dari data tersebut dapat diambil keputusan bahwa hubungan antara $X_{1}, X_{2}$, dan $\mathrm{X}_{3}$ tidak terjadi multikolinearitas. Untuk uji autokorelasi dengan nilai durbin-watson sebesar 2,311 sehingga diketahui bahwa tidak terjadi autokorelasi pada regresi linier yang dilakukan pada $\mathrm{X}_{1}, \mathrm{X}_{2}, \mathrm{X}_{3}$ dengan $\mathrm{Y}$. Hal tersebut diketahui dengan memperhatikan nilai $\mathrm{dU} \leq \mathrm{DW} \geq 4$ - $\mathrm{dU}$. Sedangkan untuk hasil uji heteroskedastisitas diperoleh simpulan tidak terjadi heteroskedastisitas, karena 
Tabel 1 Distribusi Variabel Kemampuan Adaptasi terhadap Dunia Kerja

\begin{tabular}{cllcc}
\hline No & \multicolumn{1}{c}{ Interval } & \multicolumn{1}{c}{ Klasifikasi } & F & \% \\
\hline 1 & $69,25-84$ & Sangat Baik & 6 & 6,25 \\
2 & $53,5-68,25$ & Baik & 72 & 75,00 \\
3 & $37,75-52,5$ & Kurang Baik & 18 & 18,75 \\
4 & $21-36,75$ & Tidak Baik & 0 & 0 \\
\hline \multicolumn{2}{c}{ Jumlah } & $\mathbf{9 6}$ & $\mathbf{1 0 0 \%}$ \\
\hline
\end{tabular}

Tabel 2 Distribusi Variabel Self-Regulated Learning

\begin{tabular}{cclcc}
\hline No & Interval & Klasifikasi & F & \% \\
\hline 1 & $72,5-88$ & Sangat Tinggi & 16 & 16,67 \\
2 & $56-71,5$ & Tinggi & 71 & 73,96 \\
3 & $39,5-55$ & Sedang & 9 & 9,38 \\
4 & $22-38,5$ & Rendah & 0 & 0 \\
\hline \multicolumn{2}{c}{ Jumlah } & $\mathbf{9 6}$ & $\mathbf{1 0 0 \%}$ \\
\hline
\end{tabular}

Tabel 3 Distribusi Variabel Kemampuan Komunikasi

\begin{tabular}{|c|c|c|c|c|}
\hline No & Interval & Klasifikasi & $\mathbf{F}$ & $\%$ \\
\hline 1 & $49,25-60$ & Sangat Tinggi & 10 & 10,42 \\
\hline 2 & $38,5-48,25$ & Tinggi & 70 & 72,92 \\
\hline 3 & $27,25-37,5$ & Sedang & 16 & 16,66 \\
\hline 4 & $15-26,25$ & Tidak Tinggi & 0 & 0 \\
\hline \multicolumn{3}{|c|}{ Jumlah } & 96 & $100 \%$ \\
\hline
\end{tabular}

Tabel 4 Distribusi Variabel Vocational Skills

\begin{tabular}{cllcc}
\hline No & \multicolumn{1}{c}{ Interval } & \multicolumn{1}{c}{ Klasifikasi } & F & \% \\
\hline 1 & $108,25-132$ & Sangat Tinggi & 38 & 39,58 \\
2 & $51-75$ & Tinggi & 53 & 55,21 \\
3 & $26-50$ & Sedang & 5 & 5,21 \\
4 & $0-25$ & Rendah & 0 & 0 \\
\hline \multicolumn{2}{c}{ Jumlah } & $\mathbf{9 6}$ & $\mathbf{1 0 0 \%}$ \\
\hline
\end{tabular}

pada diagram scatterplot titik-titik menyebar tidak membentuk suatu pola yang jelas dan tersebar di atas dan di bawah angka nol pada sumbu Y.

Berdasarkan uji asumsi diketahui bahwa data penelitian memenuhi semua uji asumsi, sehingga data penelitian selanjutnya dianalisis dengan analisis regresi (secara parsial dan simultan). Analisis data hubungan variabel self-regualted learning dengan kemampuan adaptasi terhadap dunia kerja disajikan pada Tabel 5.

Analisis data hubungan variabel kemampuan komunikasi dengan kemampuan adaptasi terhadap dunia kerja disajikan pada Tabel 6 .

Analisis data hubungan variabel vocational skills dengan kemampuan adaptasi terhadap dunia kerja disajikan pada Tabel 7.

Analisis data hubungan variabel selfregualted learning dan kemampuan komunikasi dengan kemampuan adaptasi terhadap dunia kerja disajikan pada Tabel 8.

Analisis data hubungan variabel self-regualted learning dan vocational skills dengan kemampuan adaptasi terhadap dunia kerja disajikan pada Tabel 9.

Analisis data hubungan variabel kemampuan komunikasi dan vocational skills dengan kemampuan adaptasi terhadap dunia kerja disajikan pada Tabel 10.

Analisis data hubungan variabel self-regualted learning, kemampuan komunikasi, dan vocational skills dengan kemampuan adaptasi terhadap dunia kerja disajikan pada Tabel 11.

Uji Hipotesis untuk mengungkap hubungan antara $X_{1}, X_{2}$, dan $X_{3}$ secara simultan dengan $\mathrm{Y}$ adalah positif dan signifikan diperoleh nilai sig. $=0,000<0,05$. Dari hasil penelitian didapat persamaan regresi $\mathrm{Y}=17,818+0,448 \mathrm{X}_{1}+0,351$ $\mathrm{X}_{2}-0,010$. Persamaan regresi tersebut dijelaskan 
Tabel 5 Hasil Analisa Parsial $X_{1}$ dengan $Y$

\begin{tabular}{cccccc}
\hline $\mathbf{R}$ & $\mathbf{R}$ Square & Sum of Squares & Means Square & $\mathbf{t}$ & Sig. \\
\hline 0,592 & 0,351 & 1452,723 & 1452,723 & 50,773 & .000 \\
\hline
\end{tabular}

Tabel 6 Hasil Analisa Parsial $X_{2}$ dengan $Y$

\begin{tabular}{cccccc}
\hline $\mathbf{R}$ & R Square & Sum of Squares & Means Square & $\mathbf{t}$ & Sig. \\
\hline 0,512 & 0,262 & 1085,461 & 1085,461 & 33,379 & .000 \\
\hline
\end{tabular}

Tabel 7 Hasil Analisa Parsial $X_{3}$ dengan $Y$

\begin{tabular}{cccccc}
\hline $\mathbf{R}$ & $\mathbf{R}$ Square & Sum of Squares & Means Square & $\mathbf{t}$ & Sig. \\
\hline 0,443 & 0,196 & 331.246 & 331,246 & 8,052 & .000 \\
\hline
\end{tabular}

Tabel 8 Hasil Analisa Regresi $X_{1}$ dan $X_{2}$ dengan $Y$

\begin{tabular}{cccccc}
\hline $\mathbf{R}$ & $\mathbf{R}$ Square & Sum of Squares & Means Square & $\mathbf{F}$ & Sig. \\
\hline 0,642 & 0,413 & 1709,669 & 854,835 & 32,681 & .000 \\
\hline
\end{tabular}

Tabel 9 Hasil Analisa Regresi $X_{1}$ dan $X_{3}$ dengan $Y$

\begin{tabular}{cccccc}
\hline $\mathbf{R}$ & $\mathbf{R}$ Square & Sum of Squares & Means Square & $\mathbf{F}$ & Sig. \\
\hline 0,661 & 0,437 & 738,102 & 369,051 & 50,773 & .000 \\
\hline
\end{tabular}

Tabel 10 Hasil Analisa Regresi $\mathrm{X}_{2}$ dan $\mathrm{X}_{3}$ dengan $\mathrm{Y}$

\begin{tabular}{cccccc}
\hline $\mathbf{R}$ & R Square & Sum of Squares & Means Square & F & Sig. \\
\hline 0,642 & 0,412 & 694,991 & 369,051 & 11,190 & .000 \\
\hline
\end{tabular}

Tabel 11 Hasil Analisa Regresi $X_{1}, X_{2}$ dan $X_{3}$ dengan $Y$

\begin{tabular}{cccccc}
\hline $\mathbf{R}$ & $\mathbf{R}$ Square & Sum of Squares & Means Square & $\mathbf{F}$ & Sig. \\
\hline 0,697 & 0,486 & 821,395 & 273,798 & 9,786 & .000 \\
\hline
\end{tabular}

bahwa nilai $Y$ akan dipengaruhi nilai $\mathrm{X}_{1}, \mathrm{X}_{2}$, dan $\mathrm{X}_{3}$ secara simultan, artinya ketika nilai $\mathrm{X}_{1}$ dan $\mathrm{X}_{2}$ tidak mengalami kenaikan dan nilai $\mathrm{X}_{3}$ tidak mengalami penurunan atau ketiganya bernilai 0 secara konstan, maka nilai Y secara konstan akan bernilai 17,818. Jika nilai $\mathrm{X}_{1}$ dan nilai $\mathrm{X}_{2}$ mengalami kenaikan dan $\mathrm{X}_{3}$ mengalami penurunan satu satuan secara simultan maka nilai Y merupakan hasil dari 17,818 ditambah $0,448 \mathrm{X}_{1}$ dan $0,351 \mathrm{X}_{2}$ serta dikurangi $0,010 \mathrm{X}_{3}$.

Sumbangan yang diberikan variabel bebas $\mathrm{X}_{1}$, $\mathrm{X}_{2}$, dan $\mathrm{X}_{3}$ secara simultan terhadap variabel terikat Y sebesar $48,6 \%$. Sedangkan $51,4 \%$ dipengaruhi oleh variabel dan faktor lain yang tidak diteliti dalam penelitian. Dari hasil penelitian dilihat bahwa nilai koefisien determinasi dengan nilai tertinggi adalah hubungan $\mathrm{X}_{1}, \mathrm{X}_{2}$, dan $\mathrm{X}_{3}$ dengan $\mathrm{Y}$ secara simultan.

\section{PEMBAHASAN}

Berdasarkan hasil analisa yang dilakukan diketahui bahwa terdapat hubungan yang positif dan signifikan antara SRL $\left(\mathrm{X}_{1}\right)$ dengan kemampuan adaptasi terhadap dunia kerja (Y). Kontrol diri yang baik akan membuat siswa dapat menyelesaikan tuntutan yang diberikan dengan baik, sehingga keberadaannya akan cepat diterima karena tidak merugikan orang lain disekitarnya. Hal tersebut diartikan dengan SRL yang baik akan membuat dirinya lebih disukai karena bisa menempatkan diri dilingkungannya. Hal ini selaras dengan penelitian yang dilakukan Isnaini (2017) menyimpulkan bahwa ada hubungan antara regulasi diri dan penyesuaian diri.

Diketahui bahwa terdapat hubungan yang positif dan signifikan antara kemampuan komunikasi $\left(\mathrm{X}_{2}\right)$ dengan kemampuan adaptasi terhadap dunia kerja (Y). Dewi, dkk., (2014) memaparkan seseorang memiliki penyesuaian diri yang baik jika mampu melakukan respons yang matang dan efisien. Respons tersebut bisa dilakukan oleh orang yang dapat memahami orang lain dengan baik serta mempunyai kemampuan untuk mengomunikasikan persaaan secara tepat. Hal ini 
selaras dengan penelitian Dewi, dkk., (2014) bahwa terdapat hubungan signifikan antara komunikasi interpersonal terhadap penyesuaian diri siswa.

Diketahui bahwa terdapat hubungan yang positif dan signifikan antara vocational skills $\left(\mathrm{X}_{3}\right)$ dengan kemampuan adaptasi terhadap dunia kerja (Y). Seseorang yang terampil akan memperlihatkan kemandirian dalam bekerja, mampu menyelesaikan pekerjaan, dan profesional (Sofyang, 2017). Artinya, dengan memiliki keterampilan akan merasa lebih nyaman, lebih percaya diri, serta mampu menyesuaikan diri dengan tuntutan kerja. Dunette memaparkan vocational skills didapatkan melalui training dan pengalaman melaksanakan tugas (Famella, dkk., 2015). Artinya seseorang yang memiliki vocational skills mempunyai pengalaman belajar, serta mengalami perkembangan dari segi intelektual, sosial, maupun emosinya sehingga dapat dikatakan siswa SMK memiliki kemampuan untuk beradaptasi dengan baik. Hasil penelitian Sofyang (2017) menjelaskan bahwa keterampilan berpengaruh positif dan signifikan terhadap kinerja seseorang.

Diketahui bahwa secara simultan terdapat hubungan yang positif dan signifikan antara selfregulated learning dan kemampuan komunikasi dengan kemampuan adaptasi terhadap dunia kerja siswa SMK Progam Keahlian Ketenaga-listrikan di Kota Malang. Rianata dan Sawitri (2015) memaparkan bahwa terdapat hubungan antara komunikasi interpersonal guru-siswa dengan selfregulated learning pada siswa. Hubungan indikator self-evaluation danself-judgement dengan indikator kemampuan memahami dan menyelesaikan konflik berpengaruh dan saling mendukung. Siswa yang memiliki presepsi yang baik terhadap diri sendiri dalam melakukan evaluasi strategi belajar yang diterapkan dan keinsafan diri maka terdapat kesadaran dari dalam diri siswa untuk membuat keputusan dalam mengubah perilaku agar lebih baik serta tidak menyalahkan diri sendiri secara berlebihan. Hal tersebut didukung oleh Hidayat (2015) yang memaparkan bahwa terdapat hubungan yang positif antara presepsi diri dengan pengambilan keputusan.

Seseorang dapat diterima lingkungan ketika mereka mampu berkomunikasi dengan baik, mampu merespon dengan baik, mampu memahami orang lain, dan mampu memberikan dukungan kepada orang lain. Dengan dimilikinya SRL, akan mendukung kemampuan komunikasi yang dimiliki oleh siswa, hal tersebut didukung Irawan (2017) yang memaparkan terdapat hubungan antara konsep diri dengan komunikasi interpersonal. Artinya, SRL dan kemampuan komunikasi saling mendukung satu sama lain. Oktriana (2014) dalam penelitiannya memaparkan bahwa terhadapat hubungan positifdan signifikan antararegulasiemosi dan komunikasi interpersonal dengan penyesuiaian diri. Hal tersebut mendukung penemuan yang ada pada penelitian yang dilakukan bahwa SRL dan kemampuan komunikasi berpengaruh terhadap kemampuan adaptasi terhadap dunia kerja.

Diketahui bahwa secara simultan terdapat hubungan yang positif dan signifikan antara selfregulated learning dan vocational skills dengan kemampuan adaptasi terhadap dunia kerja siswa SMK Progam Keahlian Ketenagalistrikan di Kota Malang. Kompetensi tidak akan berpengaruh optimal terhadap kinerja tanpa adanya faktor motivasi dari lingkungan sosial (Sriwidodo dan Haryanto, 2010; Gunawan, 2014; Gunawan dan Benty, 2007). Tanpa adanya kemampuan komunikasi, maka kemampuan menyesuaikan diri tidak optimal. Sehingga, tanpa adanya variabel kemampuan komunikasi, variabel vocational skills kurang dapat memberikan sumbangan terhadap kemampuan adaptasi.

Dengan adanya vocational skills yang tinggi, akan menunjang kemampuan self-regulated learning yang dimiliki siswa agar kemampuan adaptasi meningkat. Hal ini diketahui bahwa semakin tinggi kompetensi maka kinerja yang dilakukan akan semakin baik, artinya pengaturan yang terjadi akan semakin baik. Salah satu contohnya adalah dengan vocational skills yang memadai maka ketepatan waktu akan baik sehingga perencanaan yang dilakukan akan sesuai. Hal tersebut didukung Yusuf (2016) yang memaparkan kompetensi seseorang akan menunjang tugas yang diberikan sehingga hasil sesuai dengan harapan.

Diketahui bahwa secara simultan terdapat hubungan yang positif dan signifikan antara kemampuan komunikasi learning dan vocational skills dengan kemampuan adaptasi terhadap dunia kerja siswa SMK Progam Keahlian Ketenagalistrikan di Kota Malang. Sriwidodo dan Haryanto (2010) memaparkan peningkatan kompetensi 
mendukung kemampuan kerja pegawai sekaligus menentukan tingkat kinerja yang dihasilkan. Hal tersebut diartikan bahwa semakin tinggi vocational skills seseorang maka kinerja akan semakin tinggi. Dewi, dkk., (2014) memaparkan seseorang yang dikatakan memiliki penyesuaian diri yang baik jika mampu melakukan respons-respons yang baik serta dapat mengatasi konflik yang terjadi. Jika orang memiliki kinerja yang baik, berarti mereka tidak mempunyai masalah dalam melakukan pekerjaan, maka dia mampu menyelesaikan tuntutan pekerjaan sesuai dengan harapan.

Dari pemaparan tersebut dapat diketahui, vocational skills yang semakin memadai maka seseorang akan lebih menguasai dan mampu menerapkan tugas pekerjaan dengan baik. Dengan adanya kemampuan komunikasi yang baik maka individu akan dapat bekerjasama dengan lingkungannya dan melakukan adaptasi dengan baik sehingga tercipta kinerja yang efektif dan efisien. Sriwidodo dan Haryanto (2010) menyimpulkan bahwa secara parsial terdapat hubungan antara kompetensi dan komunikasi dengan kinerja pegawai. Diketahui bahwa secara bersamaan terdapat hubungan yang positif dan signifikan antara self-regulated learning, kemampuan komunikasi, dan vocational skills dengan kemampuan adaptasi terhadap dunia kerja siswa SMK Progam Keahlian Ketenagalistrikan di Kota Malang.

Noor (2015) dalam penelitiannya menyimpulkan bahwa sistem pendidikan life skills yang meliputi personal skills, social skills, vocational skills, dan specific skills berpengaruh terhadap kemandirian santri. Siswa dapat melakukan adaptasi dengan lingkungan kerja dengan dimilikinya self-regulated learning. Tentunya siswa akan siap dalam mencapai tujuan menyelesaikan pekerjaan dengan strategi yang dibuat sesuai dengan dirinya sendiri sehingga terciptalah perencanaan kerja yang akan menunjang dirinya secara personal dalam lingkungan kerja. Kalenda dan Vavrova (2016) memaparkan SRL membantu dalam menjalankan profesi, karena mempengaruhi kognitif dan metakognitif serta kondisi sosial siswa. Kemampuan komunikasi yang baik, akan membuat siswa mampu menyelesaikan permasalahan dalam lingkungan sosialnya sehingga kenyamanan dalam bekerja dapat berkurang yang berarti bahwa adaptasi di lingkungan kerja buruk.

Yu dan Ko (2016) memaparkan bahwa dengan adanya kemampuan komunikasi akan membantu untuk membangun hubungan kerjsama sebagai tim, sehingga pekerjaan akan selesai dengan efisien dan efektif. Selain faktor tersebut, tuntutan kerja yang tinggi memerlukan kompetensi kerja atau vocational skills agar karir kerja dapat berjalan sesuai dengan harapan. Cacciolatti, dkk., (2017) memaparkan personel yang mempunyai keterampilan akan dapat berkontribusi pada organisasi, artinya keterampilan akan sangat berguna untuik mengembangkan organisasi, sehingga bisa dikatakan keterampilan mendukung kemampuan adaptasi. Dengan terciptanya lingkungan kerja yang sehat, maka tidak akan ada ancaman untuk diri sendiri maupun orang lain.

Hal tersebut berarti bahwa adaptasi dilakukan dengan baik di lingkungan kerja. Blanchard dan Hersey memaparkan diperlukannya kemampuan teknis, kemampuan konseptual, dan kemampuan sosial untuk mencapai penyesuaian diri yang baik (Gunawan, 2017; Kristiani, dkk., 2013). Kemampuan teknis merupakan vocational skills, kemampuan konseptual dijelaskan sebagai selfregulated learning, sedangkan kemampuan sosial adalah kemampuan komunikasi. Hal tersebut selaras dengan hasil penelitian, diketahui bahwa koefisien yang didapatkan secara simultan ketiga variabel tersebut dengan kemampuan adaptasi dengan dunia kerja merupakan yang tertinggi dibandingkan koefisien determinasi hubungan variabel bebas dan terikat secara parsial maupun regresi berganda linier dua variabel bebas terhadap variabel terikat.

Hal tersebut dapat dilihat pada Tabel 1. Putro (2014) mengemukakan bahwa untuk mengembangkan kemampuan adaptasi siswa, seorang guru dapat melakukan beberapa hal dalam pembelajaran dengan memperhatikan faktor: selfregulated learning dan social persuasion atau pemberian dorongan pujian motivasi secara verbal, dan mastery experience atau penguasaan atas sesuatu yang didapat dari pengalaman dan usaha. Berdasarkan paparan yang tersebut, dapat diketahui bahwa untuk meningkatkan kemampuan adaptasi terhadap dunia kerja siswa SMK Progam Keahlian Ketenagalistrikan di Kota Malang dapat dilakukan dengan memperhatikan self-regulated learning, kemampuan komunikasi, dan vocational skills. 


\section{KESIMPULAN}

Berdasarkan hasil penelitian yang telah dilakukan dapat diperoleh kesimpulan: Secara simultan terdapat hubungan yang positif dan signifikan antara self-regulated learning dengan kemampuan adaptasi terhadap dunia kerja siswa SMK Progam Keahlian Ketenagalistrikan di Kota Malang. Secara simultan terdapat hubungan yang positifdansignifikanantarakemampuankomunikasi dengan kemampuan adaptasi terhadap dunia kerja siswa SMK Progam Keahlian Ketenagalistrikan di Kota Malang. Secara simultan terdapat hubungan yang positif dan signifikan antara vocational skills dengan kemampuan adaptasi terhadap dunia kerja siswa SMK Progam Keahlian Ketenagalistrikan di Kota Malang. Secara simultan terdapat hubungan yang positif dan signifikan antara self-regulated learning dan kemampuan komunikasi dengan kemampuan adaptasi terhadap dunia kerja siswa SMK Progam Keahlian Ketenagalistrikan di Kota Malang. Secara simultan terdapat hubungan yang positif dan signifikan antara self-regulated learning dan vocational skills dengan kemampuan adaptasi terhadap dunia kerja siswa SMK Progam Keahlian Ketenagalistrikan di Kota Malang. Secara simultan terdapat hubungan yang positif dan signifikan antara kemampuan komunikasi dan vocational skills dengan kemampuan adaptasi terhadap dunia kerja siswa SMK Progam Keahlian Ketenagalistrikan di Kota Malang. Secara simultan terdapat hubungan yang positif dan signifikan antara self-regulated learning, kemampuan komunikasi, dan vocational skills dengan kemampuan adaptasi terhadap dunia kerja siswa SMK Progam Keahlian Ketenagalistrikan di Kota Malang.

\section{DAFTAR RUJUKAN}

Cacciolatti, L., Lee, S. H., dan Molinero, C. M. 2017. Clashing Institutional Interests in Skills between Government and Industry: An Analysis of Demand for Technical and Soft Skills of Graduates in the UK. Journal Technological dan Social Change, 12, 15-21.

Dewi, K. K. S., Sedanayasa, G., dan Antari, N. N. M. 2014. Kontribusi Kualitas Komunikasi Interpersonal terhadap Penyesuaian Diri Siswa Kelas VIII SMP Negeri Sawan Tahun Pelajaran 2013/2014. E-journal Undiksa
Jurusan Bimbingan Konseling, 2(1), 26-34.

Famella., Setyanti, S. W. L. H., dan Mufidah, A. 2015. Pengaruh Keterampilan Kerja, Pengalaman Kerja, dan Sikap Kerja terhadap Kinerja Karyawan pada Perusahaan Rokok Gagak Hitam Kabupaten Bondowoso. Tesis tidak diterbitkan. Jember: Fakultas Ekonomi Universitas Negeri Jember.

Gunawan, I. 2013. Statistika untuk Kependidikan Sekolah Dasar. Yogyakarta: Penerbit Ombak.

Gunawan, I. 2014. Pengaruh Supervisi Pengajaran dan Kemampuan Guru Mengelola Kelas terhadap Motivasi Belajar Siswa. Ilmu Pendidikan: Jurnal Kajian Teori dan Praktik Kependidikan, 41(1), 44-52.

Gunawan, I. 2016. Pengantar Statistika Inferensial. Jakarta: Rajawali Pers.

Gunawan, I. 2017. Landasan Dasar Pendidikan. Malang: Universitas Negeri Malang, Penerbit UM Press.

Gunawan, I., dan Benty, D. D. N. 2007. Musyawarah Guru Mata Pelajaran dan Kemampuan Mengelola Kelas untuk Meningkatkan Motivasi Belajar Siswa. Manajemen Pendidikan, 20(1), 21-31.

Gunawan, I., dan Benty, D. D. N. 2017. Manajemen Pendidikan: Suatu Pengantar Praktik. Bandung: Alfabeta.

Gunawan, I., dan Palupi, A. R. 2012. Taksonomi Bloom - Revisi Ranah Kognitif: Kerangka Landasan untuk Pembelajaran, Pengajaran, dan Penilaian. Premiere Educandum Jurnal Pendidikan Dasar dan Pembelajaran, 2(2), 98-117.

Haludhi, P. D. F. 2016. Implementasi Pendidikan Life Skill dengan Metode Pray, Attitude, Knowledge, Skill, Action (PAKSA) di Transformer Center Batu. Skripsi tidak diterbitkan. Malang: Universitas Negeri Malang.

Hidayat, H. N. 2015. Pengaruh Persepsi Terhadap Keputusan Pembelian Melalui Motivasi Konsumen. Jurnal Investasi, 1(1), 19-35.

Irawan, S. 2017. Pengaruh Konsep Diri terhadap Komunikasi Interpersonal Mahasiswa. Scholaria, 7(1), 29-48.

Isnaini, F. 2017. Hubungan antara Regulasi Diri dengan Penyesuaian Diri Santri Pondok Pesantren di Surakarta. Skripsi tidak 
diterbitkan. Malang: Fakultas Psikologi Universitas Negeri Malang.

Kalenda, J., dan Vavrova, S. 2016. Self-Regulated Learning in Students of Helping Professions. Procedia Social and Behavioral Sciences, 217, 282-292.

Kartiwa, T. 2012. Daya Tarik Penyanyi Dangdut dalam Saweran pada Hiburan Dangdut (Studi Deskriptif tentang Daya Tarik Penyanyi Dangdut dalam Saweran pada Hiburan Dangdut di Kota Bandung). Skripsi tidak diterbitkan. Bandung: Universitas Komputer Indonesia.

Kemendikbud. 2017. Kompetensi Inti dan Kompetensi Dasar Mata Pelajaran Muatan Nasional (A), Muatan Kewilayahan (B), Dasar Bidang Keahlian (C1), Dasar Progam Keahlian (C2), dan Kompetensi Keahlian (C3). Jakarta: Kemendikbud.

Kristiani, D. A., Pradhanawati. A., dan Wijayanto. A. 2013. Pengaruh Kemampuan Kerja dan Motivasi Kerja terhadap Kinerja Karyawan. Jurnal Sosial Politik, 14, 1-7.

Marganingtias, P. E. 2009. Hubungan Penyesuaian Diri dengan Kekerasan Teman Sebaya pada Siswa SMK Negeri Kota Probolinggo. Skripsi Tidak diterbitkan. Malang: Fakultas Pendidikan Psikologi Universitas Negeri Malang.

Noor, A. H. 2015. Pendidikan Kecakapan Hidup (Life Skill) di Pondok Pesantren dalam Meningkatkan Kemandirian Santri. Jurnal Empowerment, 3(1), 1-31.

Oktriana, R. 2014. Hubungan antara Kemampuan Regulasi Emosidan Komunikasi Interpersonal dengan Penyesuaian Diri Siswa Sekolah Menengah Musik (SMK Negeri 2 Kasihan Bantul). Skripsi tidak diterbitkan. Surakarta: Fakultas Kedokteran Universitas Negeri Surakarta.

Permatasari, V., dan Gamayanti, W. 2016. Gambaran Penerimaan Diri (SelfAcceptance) pada Orang yang Mengalami Skizofrenia. Jurnal Ilmiah Psikologi, 3(1), 139-152.

Probowati, D. 2015. Pengembangan Paket Pelatihan Self-Regulated Learning untuk Meningkatkan Disiplin Belajar Bagi Siswa SMA. Skripsi tidak diterbitkan. Malang:
Fakultas Ilmu Pendidikan Universitas Negeri Malang.

Purita, A. 2015. Peningkatan Kemampuan Komunikasi Interpersonal pada Siswa Sekolah Menegah Kejuruan (SMK) $\mathrm{X}$ di Yogyakarta melalui Pelatihan Asertivitas. Jurnal Intervensu Psikologi, 7(2), 233-245.

Puspitasari, D. 2015. Hubungan Kecemasan dengan Kemampuan Penyesuaian Diri Warga Binaan di Lembaga Pemasyarakatan Kelas 1 Malang. Skripsi tidak diterbitkan. Malang: Universitas Negeri Malang.

Putro, S. C. 2014. Pengintegrasian Social Cognitive pada Kurikulum S1 Pendidikan Teknik Elektro LPTK untuk Memfasilitasi Kemampuan Beradaptasi Calon Guru Kejuruan. Prosiding APTEKINDO ke 7, hlm. 1001-1017.

Putro, S. C. 2017. Muatan Social Cognitive untuk Memfasilitasi Pengembangan Kemampuan Adaptasi Calon Guru pada Kurikulum Prodi S1 PTE di LPTK. Disertasi tidak diterbitkan. Malang: Universitas Negeri Malang.

Rianata, L., dan Sawitri, D. R. 2015. Hubungan antara Komunikasi Interpersonal GuruSiswa dengan Self-Regulated Learning pada Siswa SMAN 9 Semarang. Jurnal Empati, 4(2), 209-213.

Sanjaya,B.2010.Hubunganantara Kecerdasan Emosional dan Keterampilan Komunikasi Interpersonal dengan Penyesuaian diri siswa SMA Negeri se-Kabupaten Tulungagung. Skripsi tidak diterbitkan. Malang: Universitas Negeri Malang

Sofyang, F. 2017. Pengaruh Motivasi, Lingkungan Kerja, dan Keterampilan terhadap Kinerja Pegawai pada Kantor Dinas Pendapatan Pengelolaan Keuangan dan Aset Daerah Kabupaten Soppeng. Jurnal Mirai Managemen, 2(1), 79-90.

Sriwidodo, U., dan Haryanto, A. B. 2010. Pengaruh Kompetensi, Motivasi, 
Komunikasi, dan Kesejahteraan terhadap Kinerja Pegawai Dinas Pendidikan. Jurnal Manajemen Sumberdaya, 4(1), 47-57.

Yu, S., dan Ko, Y. 2016. Communication Competency as a Mediator in the Self-Leadership to Job Performance Relationship. Journal Collegian, 40, $1-5$.

Yusuf, M., Hasmin, dan Gunawan, K. Pengaruh Kompetensi, Motivasi, dan Lingkungan Kerja terhadap Tingkat Keakuratan Data Retribusi pada Badan Pengelolaan Keuangan Daerah Kabupaten Soppeng. Jurnal Mirai Managemen, 3(1), 249-265. 